\title{
Joint Measurements of Leukocyte Elastase and Myeloperoxidase Promote Identification of the State of Neutrophils in Diabetic Patients
}

\author{
Michael Alexandrovski, ${ }^{1, *}$ Soimita Suciu, ${ }^{2}$ and Jakob Alexandrovski ${ }^{3}$
}

\begin{abstract}
The clinic of diabetes mellitus (DM) offers a number of hypotheses about the leading role of polymorphonuclear neutrophils (PMNs) in both oxidative stress and diabetic complications. However, the results of numerous studies are extremely controversial. Why is it so? We appreciated the clinical significance of simultaneous measurement data of several PMN parameters, which must complement each other. For this purpose, myeloperoxidase (MPO) and elastase (EL) were jointly analyzed in the blood plasma from 160 type 2 diabetes mellitus patients with high levels of $\mathrm{HbA}_{1 c}$. A weakly positive correlation $(r \sim 0.56)$ was observed between MPO and EL analytical data, and any correlation between the concentrations of $\mathrm{MPO} / \mathrm{EL}$ and $\mathrm{HbA}_{1 c}$ was absent. Medians of 160 measurements of MPO/EL concentrations were $~ 103 / 190 \mathrm{ng} / \mathrm{mL}$, and $95 \%$ of all results were in the range below $320 / 1016 \mathrm{ng} / \mathrm{mL}$, respectively. The share of DM patients whose concentrations of MPO, EL, or either of two parameters exceeded the corresponding reference values was $65 \%, 80 \%$, and $82.5 \%$, respectively. These findings-a high intensity of neutrophil degranulation process-indicated that some diabetic conditions promote the transfer of PMNs to an "arousal" or "subactivation" state, which is identical or similar to their activation, providing in vivo an almost inexhaustible source of extremely "aggressive" MPO and EL. Thus, the conjoint MPO/EL measurements confirm the leading role of PMNs in the development of various complications of diabetes. The paradox is that the diagnostic significance of MPO/EL as independent parameters in diabetic patients is unambiguous for a number of reasons.
\end{abstract}

Keywords: diabetes mellitus; elastase; myeloperoxidase; neutrophils

\section{Introduction}

In practical diabetology, besides glycated hemoglobin $\left(\mathrm{HbA}_{1 \mathrm{c}}\right)$, there are very few biomarkers which could reflect an imbalance in carbohydrate metabolism. ${ }^{1}$

For pathologies with the rapid dynamics of inflammatory processes (for example, a postoperative state ${ }^{2,3}$ ), polymorphonuclear leukocytes (PMNs or neutrophils) are not only participants but also potential witnesses of the actual pathology state. On the other hand, PMNs as biomarkers are very attractive objects of research, largely due to the numerous and relative simple mon- itoring methods. Consequently, if PMNs are involved in the pathogenesis of any disease, these cells could be tried as biomarkers. Diabetes mellitus (DM) is one such illnesses. ${ }^{4}$

The clinic of DM allowed for the suggestion of a number of hypotheses about the leading role of neutrophils in the development of both oxidative stress and diabetic complications. However these hypotheses are not sufficiently supported by reliable analytical results. Generally the data about the integral evaluation of neutrophils' functional state by DM patients are surprisingly

\footnotetext{
${ }^{1}$ Spital Region Oberaargau Langenthal, Langenthal, Switzerland.

${ }^{2}$ Department of Physiology, Cluj-Napoca University of Medicine and Pharmacy, Cluj, Romania.

${ }^{3}$ Synlab MVZ Ettlingen, Ettlingen, Germany.

*Address correspondence to: Michael Alexandrovski, MD, Spital Region Oberaargau Langenthal, Sankt Urbanstrasse 67, 4900 Langenthal, Switzerland, E-mail: med.m.alex@gmail.com
}

(c) Michael Alexandrovski et al., 2020; Published by Mary Ann Liebert, Inc. This Open Access article is distributed under the terms of the Creative Commons License (http://creativecommons.org/licenses/by/4.0), which permits unrestricted use, distribution, and reproduction in any medium, provided the original work is properly cited. 
contradictory. It is difficult to choose any functional PMN parameter, which would unambiguously depend on either the level of diabetes compensation or disease per se. Moreover even the data about certain PMN protein content in the blood of diabetics are highly ambivalent.

In our studies, we tried to understand the causes of this phenomenon. Using the blood plasma of type $2 \mathrm{di}-$ abetes mellitus (T2DM) patients, we performed a parallel analysis of the two most studied PMN enzymes: myeloperoxidase (MPO) and elastase (EL). MPO, for example, can cause a number of pathological processes, such as the formation of reactive oxygen species or hypochlorous acid $(\mathrm{HOCl})$, inducing vascular damage and endothelial dysfunction. ${ }^{5-8} \mathrm{EL}$, for its part, may be responsible for the specific inactivation of $\mathrm{C1}$ inhibitor or antithrombin III: the main regulatory proteins of complement and coagulation systems. ${ }^{9,10}$ By and large, there are many single studies with one or other PMN-derived proteins which indicate their potential implications by diabetic conditions. Therefore, it was hopeful that the conclusions drawn from joint studies of two independent markers could both confirm and complement each other. As a result, we will be able to (1) evaluate the significance of MPO and EL as biomarkers by diabetes and (2) appreciate the functional state of neutrophils.

\section{Materials and Methods}

We have studied two groups of patients with T2DM in compensated $\left(\mathrm{HbA}_{1 \mathrm{c}}<5.9 \%\right)$ and noncompensated $\left(\mathrm{HbA}_{1 \mathrm{c}}>7.1-14.7 \%\right)$ states. EDTA-plasma from these patients was received from diagnostic laboratory Synevo (Cluj-Napoca, Romania) after the necessary routine research. The clinical samples recieved were de-identified and no IRB approval was required for further studies. Thus, we have obtained blood plasma with the following well-known characteristics: the concentrations of glucose and $\mathrm{HbA}_{1 \mathrm{c}}$. Blood plasma was aliquoted in $100 \mu \mathrm{L}$ plastic microtubes and stored frozen at $-25^{\circ} \mathrm{C}$ until use.

Quantitative determinations of MPO and EL concentrations in blood plasma were carried out using enzyme immunoassay tests (ELISA) provided by the BioVendor Company (Brno, Czech). All experiments were performed according to the manufacturer's instructions.

\section{Results and Discussion}

Numerous data concerning the state of "diabetic" PMNs are surprisingly contradictory. We have tried to touch on and understand this problem. It was decided to conduct joint measurements of two different PMN proteins, each of which is capable of characterizing the PMN state by itself. It was hoped that conclusions based on the results of two independent and parallel studies could both confirm and complement each other.

Table 1 shows the concentrations of MPO and EL detected in plasma specimens of 160 patients with T2DM. Sixteen samples were obtained from patients with compensated disease $\left(\mathrm{HbA}_{1 \mathrm{c}}<5.9 \%\right.$, Nr. 1-16) and 144 samples from patients with poorly compensated illness $\left(\mathrm{HbA}_{1 \mathrm{c}}>7.1 \%\right.$; Nr. 17-160). The data in Table 1 are arranged in accordance with the growth of $\mathrm{HbA}_{1 \mathrm{c}}$ concentrations in the samples. The results are also represented graphically in Figures 1 and 2, demonstrating that correlation between the measured concentrations of $\mathrm{MPO} / \mathrm{EL}$ and the corresponding concentrations of $\mathrm{HbA}_{1 \mathrm{c}}$ was absent. The concentrations of MPO and PMN-EL in the plasma of healthy donors $(n=4)$ varied in the selfsame range from 22 to $65 \mathrm{ng} / \mathrm{mL}$.

ELISA kits and the data of neutrophil-derived EL levels in plasma of healthy people were provided by BioVendor Company: the median concentration of EL was $35 \mathrm{ng} / \mathrm{mL}$ and $95 \%$ of all measurements were distributed in the concentration range $<65 \mathrm{ng} / \mathrm{mL}$. The values of the similar parameters in the plasma of patients with T2DM were $\sim 190$ and $1016 \mathrm{ng} / \mathrm{mL}$, respectively. Based on these data, it was estimated that $>80 \%$ of patients with diabetes had elevated concentrations of EL in blood. Figure 3 represents the frequencies of EL concentration distribution in the plasma samples of healthy probands and patients with T2DM.

Of course, the elevated levels of EL in blood may not necessarily only be due to the diabetic conditions, but do always indicate the presence of persistent inflammatory processes in vivo owing neutrophil activation. To verify this conclusion, MPO measurements were performed in the same clinical samples.

The detected concentrations of MPO in control plasma samples from healthy people were in the same range as in a number of publications. ${ }^{11-14}$ These results confirmed our decision to choose the recommended $95 \%$ reference limit of MPO concentrations $\sim 90.5 \mathrm{ng} / \mathrm{mL}$. This value was calculated after testing 820 plasma samples of healthy people to "provide a scientific basis for the further use of MPO in clinical practice." ${ }^{11}$ As in the case with EL, MPO concentrations in blood, which exceeded this reference value, could be considered an indicator of the presence 
Table 1. PMN-Elastase and PMN-Myeloperoxidase Concentrations in EDTA-Plasma of Good $(n=16)$ and Poorly $(n=144)$ Controlled T2DM Patients

\begin{tabular}{|c|c|c|c|c|c|c|c|c|c|c|c|c|c|c|c|}
\hline $\mathrm{Nr}$. & $\begin{array}{c}\mathrm{HbA}_{1 \mathrm{c}} \\
\%\end{array}$ & $\begin{array}{c}\text { Elastase, } \\
\mathrm{ng} / \mathrm{mL}\end{array}$ & $\begin{array}{c}\text { MPO, } \\
\text { ng/mL }\end{array}$ & Nr. & $\begin{array}{c}\mathrm{HbA}_{1 \mathrm{c}} \\
\%\end{array}$ & $\begin{array}{c}\text { Elastase, } \\
\mathrm{ng} / \mathrm{mL}\end{array}$ & $\begin{array}{c}\text { MPO, } \\
\text { ng/mL }\end{array}$ & Nr. & $\begin{array}{c}\mathrm{HbA}_{1 \mathrm{c}} \\
\%\end{array}$ & $\begin{array}{c}\text { Elastase, } \\
\mathrm{ng} / \mathrm{mL}\end{array}$ & $\begin{array}{c}\text { MPO, } \\
\text { ng/mL }\end{array}$ & Nr. & $\begin{array}{c}\mathrm{HbA}_{1 \mathrm{c}} \\
\%\end{array}$ & $\begin{array}{c}\text { Elastase, } \\
\mathrm{ng} / \mathrm{mL}\end{array}$ & $\begin{array}{c}\text { MPO, } \\
\text { ng/mL }\end{array}$ \\
\hline 1 & 5.1 & 267 & 118 & 41 & 9.2 & 238 & 98 & 81 & 10.0 & 91 & 97 & 121 & 10.7 & 116 & 116 \\
\hline 2 & 5.2 & 538 & 238 & 42 & 9.2 & 231 & 122 & 82 & 10.0 & 259 & 105 & 122 & 10.8 & 492 & 447 \\
\hline 3 & 5.3 & 230 & 152 & 43 & 9.2 & 56 & 44 & 83 & 10.0 & 303 & 160 & 123 & 10.8 & 602 & 97 \\
\hline 4 & 5.3 & 128 & 149 & 44 & 9.2 & 1095 & 121 & 84 & 10.0 & 597 & 99 & 124 & 10.8 & 308 & 149 \\
\hline 5 & 5.3 & 170 & 268 & 45 & 9.3 & 142 & 129 & 85 & 10.0 & 276 & 214 & 125 & 10.9 & 152 & 75 \\
\hline 6 & 5.3 & 45 & 48 & 46 & 9.3 & 330 & 135 & 86 & 10.1 & 212 & 118 & 126 & 11.0 & 1078 & 81 \\
\hline 7 & 5.4 & 125 & 168 & 47 & 9.3 & 86 & 45 & 87 & 10.1 & 262 & 147 & 127 & 11.0 & 33 & 20 \\
\hline 8 & 5.4 & 714 & 277 & 48 & 9.3 & 739 & 93 & 88 & 10.1 & 92 & 57 & 128 & 11.1 & 179 & 102 \\
\hline 9 & 5.4 & 89 & 132 & 49 & 9.3 & 539 & 97 & 89 & 10.1 & 65 & 56 & 129 & 11.1 & 226 & 274 \\
\hline 10 & 5.4 & 87 & 71 & 50 & 9.3 & 50 & 73 & 90 & 10.1 & 199 & 52 & 130 & 11.1 & 138 & 83 \\
\hline 11 & 5.5 & 334 & 223 & 51 & 9.3 & 460 & 85 & 91 & 10.1 & 926 & 148 & 131 & 11.2 & 1786 & 2058 \\
\hline 12 & 5.5 & 153 & 74 & 52 & 9.4 & 64 & 73 & 92 & 10.1 & 210 & 103 & 132 & 11.2 & 187 & 114 \\
\hline 13 & 5.6 & 196 & 159 & 53 & 9.4 & 46 & 51 & 93 & 10.2 & 146 & 111 & 133 & 11.2 & 36 & 72 \\
\hline 14 & 5.7 & 260 & 205 & 54 & 9.4 & 136 & 95 & 94 & 10.2 & 132 & 105 & 134 & 11.2 & 622 & 272 \\
\hline 15 & 5.8 & 50 & 84 & 55 & 9.4 & 28 & 38 & 95 & 10.3 & 931 & 118 & 135 & 11.3 & 150 & 176 \\
\hline 16 & 5.9 & 437 & 206 & 56 & 9.4 & 32 & 43 & 96 & 10.3 & 42 & 33 & 136 & 11.3 & 20 & 42 \\
\hline 17 & 7.1 & 713 & 326 & 57 & 9.5 & 611 & 151 & 97 & 10.3 & 185 & 213 & 137 & 11.3 & 84 & 108 \\
\hline 18 & 7.4 & 343 & 206 & 58 & 9.5 & 14 & 27 & 98 & 10.3 & 1061 & 537 & 138 & 11.2 & 114 & 97 \\
\hline 19 & 8.1 & 109 & 99 & 59 & 9.5 & 194 & 108 & 99 & 10.3 & 463 & 167 & 139 & 11.2 & 1167 & 148 \\
\hline 20 & 8.4 & 255 & 169 & 60 & 9.5 & 290 & 191 & 100 & 10.4 & 225 & 148 & 140 & 11.4 & 36 & 74 \\
\hline 21 & 8.4 & 82 & 41 & 61 & 9.5 & 298 & 119 & 101 & 10.4 & 923 & 326 & 141 & 11.4 & 689 & 224 \\
\hline 22 & 8.4 & 463 & 88 & 62 & 9.6 & 20 & 35 & 102 & 10.4 & 71 & 66 & 142 & 11.8 & 32 & 64 \\
\hline 23 & 8.9 & 165 & 95 & 63 & 9.6 & 250 & 97 & 103 & 10.4 & 268 & 148 & 143 & 11.8 & 71 & 50 \\
\hline 24 & 9.0 & 358 & 141 & 64 & 9.6 & 52 & 72 & 104 & 10.4 & 237 & 98 & 144 & 11.9 & 135 & 100 \\
\hline 25 & 9.0 & 305 & 166 & 65 & 9.6 & 132 & 146 & 105 & 10.4 & 650 & 138 & 145 & 12.0 & 406 & 150 \\
\hline 26 & 9.0 & 1049 & 242 & 66 & 9.6 & 162 & 72 & 106 & 10.5 & 29 & 57 & 146 & 12.0 & 82 & 100 \\
\hline 27 & 9.0 & 481 & 141 & 67 & 9.7 & 449 & 39 & 107 & 10.5 & 72 & 55 & 147 & 12.1 & 68 & 174 \\
\hline 28 & 9.0 & 240 & 134 & 68 & 9.7 & 121 & 64 & 108 & 10.5 & 17 & 50 & 148 & 12.1 & 51 & 45 \\
\hline 29 & 9.1 & 31 & 26 & 69 & 9.7 & 35 & 51 & 109 & 10.5 & 1282 & 98 & 149 & 12.2 & 84 & 118 \\
\hline 30 & 9.1 & 1016 & 313 & 70 & 9.7 & 1405 & 103 & 110 & 10.5 & 762 & 582 & 150 & 12.3 & 44 & 42 \\
\hline 31 & 9.1 & 283 & 36 & 71 & 9.7 & 73 & 110 & 111 & 10.6 & 88 & 138 & 151 & 12.6 & 58 & 83 \\
\hline 32 & 9.1 & 545 & 88 & 72 & 9.8 & 250 & 133 & 112 & 10.6 & 43 & 68 & 152 & 12.6 & 66 & 103 \\
\hline 33 & 9.1 & 23 & 50 & 73 & 9.8 & 340 & 188 & 113 & 10.6 & 474 & 102 & 153 & 12.7 & 173 & 82 \\
\hline 34 & 9.1 & 327 & 68 & 74 & 9.8 & 225 & 102 & 114 & 10.6 & 115 & 148 & 154 & 12.7 & 505 & 384 \\
\hline 35 & 9.1 & 57 & 126 & 75 & 9.8 & 22 & 21 & 115 & 10.7 & 216 & 144 & 155 & 13.0 & 24 & 54 \\
\hline 36 & 9.1 & 89 & 104 & 76 & 9.8 & 509 & 125 & 116 & 10.7 & 354 & 154 & 156 & 13.3 & 325 & 108 \\
\hline 37 & 9.2 & 515 & 78 & 77 & 9.9 & 232 & 136 & 117 & 10.7 & 185 & 22 & 157 & 13.4 & 49 & 53 \\
\hline 38 & 9.2 & 905 & 376 & 78 & 9.9 & 61 & 64 & 118 & 10.7 & 303 & 37 & 158 & 13.6 & 96 & 136 \\
\hline 39 & 9.2 & 79 & 143 & 79 & 9.9 & 187 & 127 & 119 & 10.7 & 78 & 125 & 159 & 14.7 & 146 & 169 \\
\hline 40 & 9.2 & 387 & 237 & 80 & 9.9 & 201 & 72 & 120 & 10.7 & 333 & 188 & 160 & 14.7 & 100 & 93 \\
\hline
\end{tabular}

$\mathrm{HbA}_{1 \mathrm{c}}$ glycated hemoglobin; MPO, myeloperoxidase; PMNs, polymorphonuclear leukocytes, neutrophils; T2DM, type 2 diabetes mellitus.

of in vivo inflammatory processes and infection, or the occurrence of pathologies associated with the activation of neutrophilic leukocytes. The median concentration of MPO in the blood of patients with poorly compensated T2DM was $\sim 103 \mathrm{ng} / \mathrm{mL}$, and $95 \%$ of all measurements were in the concentration range less than $\sim 320 \mathrm{ng} / \mathrm{mL}$. The quota of diabetic patients with MPO increased levels was $\sim 65 \%$. To visualize the boundary, which separates healthy and pathological, we compared the frequencies of MPO concentration distribution in the plasma from healthy probands and diabetic patients (Fig. 4).

By and large, MPO and EL are usually considered indicators of nonspecific immunity state. As well known, after neutrophil activation, both MPO and EL enzymes leave the azurophilic granules of white blood cells and enter the extracellular space. Therefore, their concentrations in the blood should be approximately equal and correlated with each other. Indeed, many similar studies in healthy people prove this. From these positions, our results were surprising and characterized by the following two remarkable features: first of all, the $95 \%$ confidence range of EL concentration distribution in plasma samples from diabetic patients was more than three times as wide (!), as for MPO. Second, the correlation coefficient between the steadystate concentrations of MPO and EL was only 0.56 (Fig. 5). The value obtained made it possible to assert the existence of only moderate positive correlation between the parameters studied. 


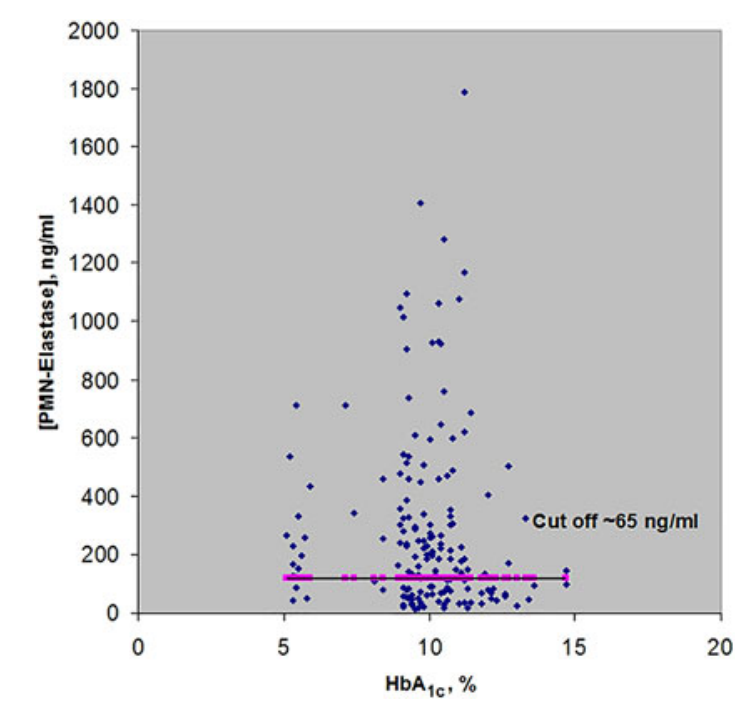

FIG. 1. Concentrations of PMN-EL in plasma of 160 patients with good $\left(\mathrm{HbA}_{1 \mathrm{c}}<5.9 \%\right)$ and poorly controlled ( $\mathrm{HbA}_{1 c}$ 7.1-14.7\%) T2DM. EL, elastase; $\mathrm{HbA}_{1 c}$, glycated hemoglobin; PMN, polymorphonuclear leukocyte, neutrophils; T2DM, type 2 diabetes mellitus.

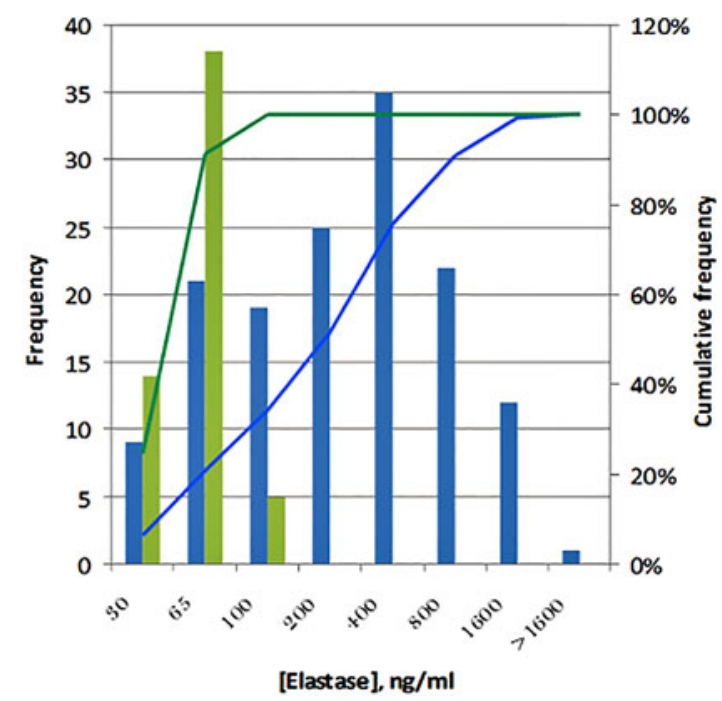

FIG. 3. Frequency distribution of PMN-EL concentrations in plasma of healthy (green) donors* and decompensate (blue) T2DM patients**. *Results from BioVendor; ${ }^{* *}$ Own research data (Table 1).

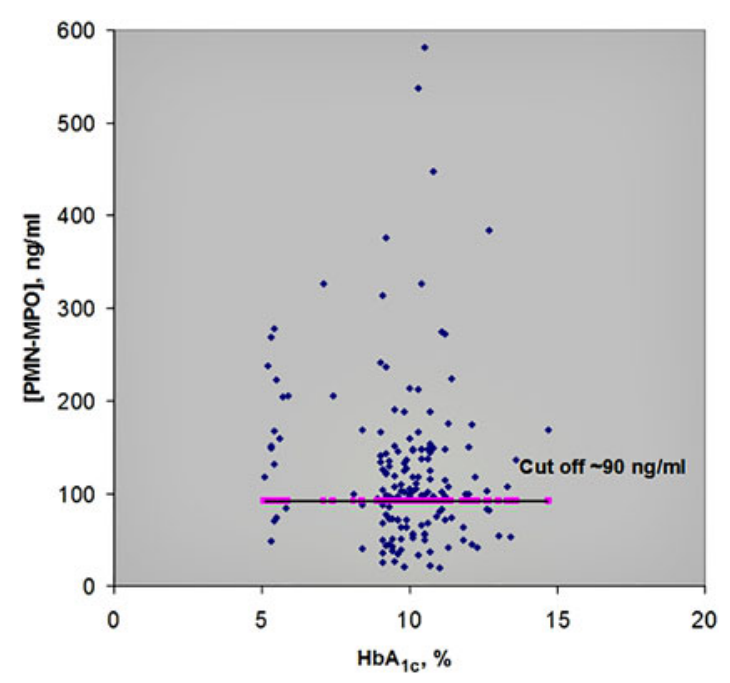

FIG. 2. Concentrations of MPO in plasma of 160 patients with good $\left(\mathrm{HbA}_{1 \mathrm{c}}<5.9 \%\right)$ and poorly controlled $\left(\mathrm{HbA}_{1 c} 7.1-14.7 \%\right) \mathrm{T} 2 \mathrm{DM}$. $\mathrm{MPO}$, myeloperoxidase.

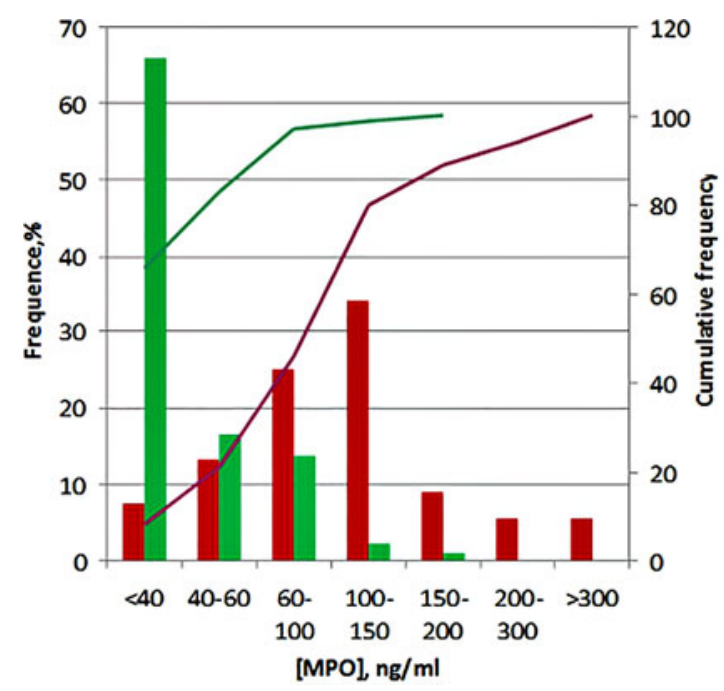

FIG. 4. Frequency distribution of MPO concentrations in plasma of healthy (green) donors* and decompensate (red) T2DM patients**. ${ }^{*}$ Results from Ref. ${ }^{11} ;{ }^{* *}$ Own research data (Table 1). 
after heparin administration, the blood MPO concentrations were greatly increased (sometimes up to two times), while concentrations of EL remained unchanged. ${ }^{2,22}$ In a series of experiments with cultured human endothelial cells, it was also shown that diabetes per se, or high glucose concentrations, contributed to phenotypic changes of the cell surfaces and caused accelerated sorption processes for both MPO and PMNs. ${ }^{23}$ These findings were also clearly confirmed by studying microvessels from rats with experimental diabetes. ${ }^{7,8}$

The process of PMN-EL occurrence in the blood has also its own remarkable features.

First, like MPO, neutrophilic EL under certain conditions can also play the role as an autoantigen. ${ }^{24}$ However, we could not find any reliable information about the presence of EL-specific autoantibodies in DM or about their influence on the results of EL enzyme immunoassay analysis.

From these positions, more attention should be paid to another property of EL. The fact is that once in the extracellular space, EL does not remain intact, and instead builds complexes with some proteins from the socalled "serpin family" (serine protease inhibitors). This interaction really affects in vivo both the concentration and enzyme activity. Therefore, taking into account the assumption made, we also evaluated the effect of this phenomenon on EL analyses.

Among the broad family of EL inhibitors, the most active is $\alpha 1$-antitrypsin. Its content in norm $(\sim 1 \mathrm{mg} / \mathrm{mL})$ is at least 10,000 times higher than the baseline level of EL in the blood. Consequently, the concentrations of the complexes formed must be correlated with concentrations of EL released from neutrophils. The BioVendore ELISA-Kit for quantitative analysis of PMN-EL is based on this principle and allows analyzing EL in the plasma samples up to $1000 \mathrm{ng} / \mathrm{mL}$. In this regard, it should be emphasized that, although the clinical material under study was obtained mainly from patients with poorly compensated diabetes, $95 \%$ of all results were also located in concentration range $<1016 \mathrm{ng} / \mathrm{mL}$. Besides, the measured EL values, as well as the range of their concentration distribution in diabetics, were in good agreement with the results of previous studies. ${ }^{25}$ Therefore, taking into account that PMN-EL does not adsorb on the surface of epithelium cells, we have concluded that the measured data of EL concentrations are reliable and correct. 
Unfortunately, a similar proposition cannot be used to evaluate the results of MPO measurements-a widespread research object in many disorders, inclusive diabetes. ${ }^{4}$ The fact is that due to the unique ability to be adsorbed on the walls of blood vessels, the MPO analytical data most likely are not able to fully reflect the true picture of the enzyme content in vivo. The degree of sorption will depend on many factors that are difficult to take into account. Therefore, even in the case of a massive influx of MPO into the bloodstream, the measured MPO concentrations in T2DM patients can be underestimated in comparison with real ones. Perhaps for this reason, the values and range of MPO concentrations in patients with diabetes did not deviate too far from reference data. The same results were also represented in many other similar studies. ${ }^{26-28}$ At the same time, we observed increased concentrations of MPO in $65 \%$ of patients with DM.

Based on the foregoing, it should be assumed that more valuable information about MPO through diabetes can be obtained by measuring not the enzyme concentration in blood, but its activity in biopsy samples. In this case, the magnitude of the analytical signal will depend not only on the enzyme dissolved but also adsorbed (immobilized) on the walls of the microvasculature. Indeed, in experiments with tissue pieces from rats with experimental diabetes, it was shown that the ratio of specific activities of MPO diabetes/ control/g of tissue reached $>300 \% .{ }^{29}$ Naturally, the practical use of this approach is unacceptable. However, these data allow us to estimate approximately the degree of MPO sorption and notice its significance in diabetes. Of course, this topic requires special research. However, it can already be argued that MPO adhesion in vivo should proceed more intensively in the capillary network due to the significant increase of the inner blood vessel surface (and, consequently, an increase of sorption area). It is highly likely that this mechanism is dominant in the pathology of diabetic angiopathy, especially considering the significantly extended lifetime of immobilized MPO in vivo (see the following discussion).

Thus, we were able to identify several potential causes, which could significantly affect the ratio of $\mathrm{MPO} / \mathrm{EL}$ concentrations in vivo. Among them, the main cause is solely the polycationic nature of MPO, which ensures its strong interactions with negatively charged surfaces of endothelial cells. ${ }^{21}$

From this point of view, the use of EL as a biomarker seems to be a more reliable and informative parameter.
Table 2. Half-Life of PMNs and Certain Proteins Involved in Diabetes Pathology

\begin{tabular}{|c|c|c|}
\hline Name & Half-life, $\tau^{1 / 2}$ & References \\
\hline $\mathrm{HbA}_{1 \mathrm{c}}$ & $\sim 28.7$ days (689h) & 35 \\
\hline Fructosamine & $\sim 16.5$ days $(396 \mathrm{~h})$ & 35 \\
\hline PMNs in blood & $\sim 6-7 \mathrm{~h}$ & 36 \\
\hline $\begin{array}{l}\text { PMN elastase in complex } \\
\text { with } \alpha 2 \text {-macroglobulin }\end{array}$ & $\sim 12 \min (0.2 \mathrm{~h})$ & 37 \\
\hline $\begin{array}{l}\text { PMN elastase in complex } \\
\text { with } \alpha 1 \text {-proteinase inhibitor }\end{array}$ & $\sim 60 \min (1 \mathrm{~h})$ & \\
\hline MPO in blood & $\sim 4 \min$ & 7,8 \\
\hline MPO immobilized on vascular wall & $\sim 4320 \min$ ( 3 days) & \\
\hline
\end{tabular}

However, it is well known that an increase of PMN-EL in the blood could be associated not only with diabetes but also with a large number of other pathologies. Therefore, in the absence of an adequate reference parameter, which will be specific especially for diabetes, it is unlikely to use only solo EL measurements as a nonspecific biomarker for mass use. ${ }^{25}$

In fact, this statement applies not only to EL but also to the neutrophils themselves or any other PMN proteins when trying to use them as diabetic biomarkers. That is why many researchers tried through diabetics to find the relationship between the different characteristics of $\mathrm{PMN}$ and $\mathrm{HbA}_{1 \mathrm{c}}$ levels. However, some discovered relationships between $\mathrm{HbA}_{1 \mathrm{c}}$ and, for example, MPO activity, ${ }^{30,31}$ amounts of neutrophil leukotriene $\mathrm{B} 4,{ }^{32}$ or activity of $\mathrm{PMN}$-alkaline phosphatase ${ }^{33}$ strangely did not coincide with the results of similar ${ }^{26,34}$ or present studies.

Apparently, the absence of such correlation between the concentrations of MPO/EL and $\mathrm{HbA}_{1 \mathrm{c}}$ in patients with T2DM can be explained if we take into account the time hierarchy of the processes under consideration and compare the life cycle durations of their participants (Table 2). As follows from the data presented in Table 2, during the lifetime of one generation of $\mathrm{HbA}_{1 \mathrm{c}}$ in vivo, at least several tens of PMN generations will be replaced. In other words, substitution of MPO or EL concentrations in blood will proceed much faster than the changes of $\mathrm{HbA}_{1 c}$ concentrations. Consequently, the content of $\mathrm{HbA}_{1 \mathrm{c}}$ in vivo in the framework of supposed correlations must be considered not as a variable, but as a constant value. This means that, even theoretically, there is no and cannot be any relationship between $\mathrm{HbA}_{1 \mathrm{c}}$ and $\mathrm{MPO} / \mathrm{EL}$ activity/concentrations.

For these reasons, the results of some recent studies, which have also indicated a positive correlation between $\mathrm{HbA}_{1 \mathrm{c}}$ levels and concentrations of certain 
proinflammatory proteins (with a clearly shorter life span than hemoglobin), such as angiopoietin-like protein- $6^{38}$ or interleukin- $6^{39}$ should be carefully reconsidered.

\section{Conclusions}

The joint measurements of MPO and EL can independently characterize the same one state of neutrophils from different "points of view." This allowed us to compare analytical meaningfulness of both the tests used and to conclude about the PMN status in patients with T2DM. It was shown that (1) the quota of patients with elevated levels of MPO and EL were $65 \%$ and $80 \%$, respectively; (2) between measured concentrations of MPO and EL was observed only a weak correlation, and (3) the 95\% range of MPO distribution among diabetic patients was only slightly different from the control and was almost three times less wide as for the EL.

To evaluate the results obtained, it was necessary to take into account not only the physicochemical properties of MPO but also mechanism of its biological activity. Namely the nature of MPO determined its "dualistic role" in vivo-on the one hand, the ability to simultaneously protect the organism from various types of bacterial infection and, on the other hand, to attack the capillary network of blood circulation under certain conditions. This phenomenon is based on the same one mechanism of MPO action: at first stage, the polycationic enzyme globules "adhere" to the negatively charged surfaces of both different pathogens or endothelial cells. This process can lead to the depletion of MPO in the bloodstream even during powerful enzyme inflow from activated neutrophils. That is why MPO concentrations in diabetic patients may not differ significantly from normal values and the quota of DM patients with elevated MPO levels was depressed compared with EL test.

At the same time, the joint MPO and EL measurements unequivocally indicated the high intensity of PMNs degranulation processes in the blood of diabetic patients. That means that diabetes promotes the transition of neutrophils into a state of "subactivation," which is identical or similar to the state of activated PMNs. Therefore, it can be argued that MPO and EL really take an active part in numerous pathological processes in diabetes. The paradox is that the diagnostic significance of MPO (especially) or EL as independent solo "diabetic" biomarkers may be in some cases not only uninformative but even erroneous.

\section{Authors' Contributions}

The article was written through contributions of all authors. All authors have given approval to the final version of the article.

\section{Acknowledgments}

The authors would like to thank Rene Huvar and Dr. Vladimir Kolar from the BioVendor Laboratories Ltd. (Brno, Czech Republic) for providing test kits and Dr. Lytitia Blag from the Synevo laboratory (Cluj, Romania) for providing clinical samples.

\section{Author Disclosure Statement}

No competing financial interests exist.

\section{Funding Information}

No funding was received for this article.

\section{References}

1. Goetze JP, Sonne DP. Diabetes and its lack of causal biomarkers. Biomark Med. 2016;10:1121-1123.

2. Faymonville ME, Pincemail J, Duchateau J, et al. Myeloperoxidase and elastase as markers of leukocyte activation during cardiopulmonary bypass in humans. J Thorac Cardiovasc Surg. 1991;102:309-317.

3. Olza J, Aguilera CM, Gil-Campos M, et al. Myeloperoxidase is an early biomarker of inflammation and cardiovascular risk in prepubertal obese children. Diabetes Care. 2012;35:2373-2376.

4. Khan AA, Alsahli MA, Rahmani AH. Myeloperoxidase as an active disease biomarker: recent biochemical and pathological perspectives. Med Sci. 2018;6:33

5. Ridzuan N, John CM, Sandrasaigaran P, et al. Preliminary study on overproduction of reactive oxygen species by neutrophils in diabetes mellitus. World J Diabetes. 2016;7:271-278.

6. Johnson RJ, Klebanoff SJ, Ochi RF, et al. Participation of the myeloperoxidase-H2O2-halide system in immune complex nephritis. Kidney Int. 1987;32:342-349.

7. Zhang C, Yang J, Jennings LK. Leukocyte-derived myeloperoxidase amplifies high-glucose-induced endothelial dysfunction through interaction with high-glucose-stimulated, vascular non-leukocyte-derived reactive oxygen species. Diabetes. 2004;53:2950-2959.

8. Rovira-Llopis S, Rocha M, Falcon R, et al. Is myeloperoxidase a key component in the ROS-induced vascular damage related to nephropathy in type 2 diabetes? Antioxid Redox Signal. 2013;19:1452-1458.

9. Carrell RW, Owen MC. Plakalbumin, alpha 1-antitrypsin, antithrombin and the mechanism of inflammatory thrombosis. Nature. 1985;317: 730-732.

10. Browerg MS, Harpel PC. Proteolytic cleavage and inactivation of alfa2plasmin inhibitor and $\mathrm{C} 1$ inactivator by human polymorphonuclear leukocyte elastase. J Biol Chem. 1982;257:9849-9854.

11. Ma Chun-mei, Wu Jian-rong, Ye Dao-bin, et al. Determination of a reference value for plasma myeloperoxidase in healthy Chinese population. Life Sci J. 2015;12:89-93.

12. Vita JA, Brennan ML, Gokce N, et al. Serum myeloperoxidase levels independently predict endothelial dysfunction in humans. Circulation. 2004;110:1134-1139.

13. Hoy A, Tregouet D, Leininger-Muller B, et al. Serum myeloperoxidase concentration in a healthy population: biological variations, familial resemblance and new genetic polymorphisms. Eur J Hum Genet. 2001;9: 780-786.

14. Kubala L, Lu G, Baldus S, et al. Plasma levels of myeloperoxidase are not elevated in patients with stable coronary artery disease. Clin Chim Acta. 2008;394:59-62

15. Guilpain P, Servettaz A, Batteux F, et al. Natural and disease associated antimyeloperoxidase (MPO) autoantibodies. Autoimmun Rev. 2008;7:421-425. 
16. Accardo-Palumbo A, Triolo G, Giardina E, et al. Detection of antimyeloperoxidase antibodies in the serum of patients with type 1 diabetes mellitus. Acta Diabetol. 1996;33: 103-107.

17. Parlapiano C, Marangi M, Campana E, et al. Anti-neutrophil cell antibodies in newly diagnosed patients with type1 diabetes. Exp Clin Endocrinol Diabetes. 1999;107:328-329.

18. Keven K, Akar H, Kutlay S, et al. MPO-ANCA-associated pulmonary-renal vasculitis in a patient with diabetes mellitus. J Nephrol. 2002;15:720-723.

19. Schlaffke J, Zozulińska D, Wierusz-Wysocka B. Assessment of antineutrophil- cytoplasmic autoantibodies (ANCA) in type 1 diabetic patients. Pol Arch Med Wewn. 2005;113:552-556.

20. Haapala AM, Soppi E, Hyöty H. Circulating myeloperoxidase may cause false negative findings in the analysis of myeloperoxidase antibodies in systemic vasculitis. Scand J Immunol. 1994;40:317-322.

21. Miyasaki KT, Zambon JJ, Jones CA, et al. Role of high-avidity binding of human neutrophil myeloperoxidase in the killing of Actinobacillus actinomycetemcomitans. Infect Immun. 1987;55:1029-1036.

22. Baldus $S$, Rudolph $V$, Roiss $M$, et al. Heparins increase endothelial nitric oxide bioavailability by liberating vessel-immobilized myeloperoxidase. Circulation. 2006;113:1871-1878.

23. Okayama $\mathrm{N}$, Omi H, Okouchi M, et al. Mechanisms of inhibitory activity of the aldose reductase inhibitor, epalrestat, on high glucose-mediated endothelial injury: neutrophil-endothelial cell adhesion and surface expression of endothelial adhesion molecules. J Diabetes Complications. 2002;16:321-326.

24. Apenberg S, Andrassy K, Wörner I et al. Antibodies to neutrophil elastase: a study in patients with vasculitis. Am J Kid Dis. 1996;28:178-185.

25. Piwowar A, Knapik-Kordecka M and Warwas M. Concentration of leukocyte elastase in plasma and polymorphonuclear neutrophil extracts in type 2 diabetes. Clin Chem Lab Med. 2000;38:1257-1261.

26. Wiersma JJ, Meuwese MC, van Miert JN, et al. Diabetes mellitus type 2 is associated with higher levels of myeloperoxidase. Med Sci Monit. 2008; 14:406-410.

27. Shetty S, Kumari S, Madhu LN. Variations in Serum-Mieloperoxidase Levels with respect to Hyperglycemia, duration of diabetes, BMI, sex and aging in T2DM. Int J Res Pharm Biomed Sci. 2012;3:652-655.

28. Garcia AG, Rodriguez MR, Alonso CG, et al. Myeloperoxidase is associated with insulin resistance and inflammation in overweight subjects with first-degree relatives with type 2 Diabetes Mellitus. Diabetes Metab J. 2015;39:59-65.

29. Maheshwari RA, Balaraman R, Sen AK, et al. Effect of coenzyme Q10 alone and its combination with metformin on streptozotocin-nicotinamideinduced diabetic nephropathy in rats. Indian J Pharmacol. 2014;46:627-632.

30. Sato N, Shimizu H, Suwa K, et al. MPO activity and generation of active $\mathrm{O}_{2}$ species in leukocytes from poorly controlled diabetic patients. Diabetes Care. 1992;15:1050-1052.

31. Unubol M, Yavasoglu I, Kacar F, et al. Relationship between glycemic control and histochemical myeloperoxidase activity in neutrophils in patients with type 2 diabetes. Diabetol Metab Syndr. 2015;7:119.
32. Parlapiano $C$, Danese $C$, Marangi $M$, et al. The relationship between glycated hemoglobin and polymorphonuclear leukocyte leukotriene B4 release in people with diabetes mellitus. Diabetes Res Clin Pract. 1999;46: 43-45.

33. Tsavaris NB, Pangalis GA, Variami E, et al. Association of neutrophil alkaline phoshatase activity and glycosylated haemoglobin in diabetes mellitus. Acta Haemat. 1990;83:22-25.

34. Collier A, Jackson M, Bell D, et al. Neutrophil activation detected by increased neutrophil elastase activity in type 1 (insulin-dependent) diabetes mellitus. Diabetes Res. 1989;10:135-138.

35. Tak T, Tesselaar K, Pillay J, et al. What's your age again? Determination of human neutrophil half-lives revisited. J Leukoc Biol. 2013;94:595-601.

36. Ohlsson K, Laurell CB. The disappearance of enzyme-inhibitor complexes from the circulation of man. Clin Sci Mol Med. 1976;51:87-92.

37. McCord JM. Oxygen Free Radicals: release and Activities. A superoxideactivated chemotactic factor and its role in the inflammatory process. Agents Actions. 1980;10:522-527.

38. Sharma V, Pangtey GS, Gupta R, et al. Correlation of long-term glycemic control as measured by glycated hemoglobin with serum angiopoietinlike 6 protein levels in type 2 diabetes mellitus patients. Indian J Pharmacol. 2017;49:250-253.

39. Sari MI, Tala ZZ, Wahyuni DD. Association between glycated hemoglobin with the levels of serum proinflammatory cytokines and antioxidants in patients with type 2 diabetes mellitus in Universitas Sumatera Utara Hospital. Open Access Maced J Med Sci. 2019;7:715-720.

Cite this article as: Alexandrovski M, Suciu S, Alexandrovski J (2020) Joint measurements of leukocyte elastase and myeloperoxidase promote identification of the state of neutrophils in diabetic patients, BioResearch Open Access 9:1, 190-197, DOI: 10.1089/biores.2020.0012.

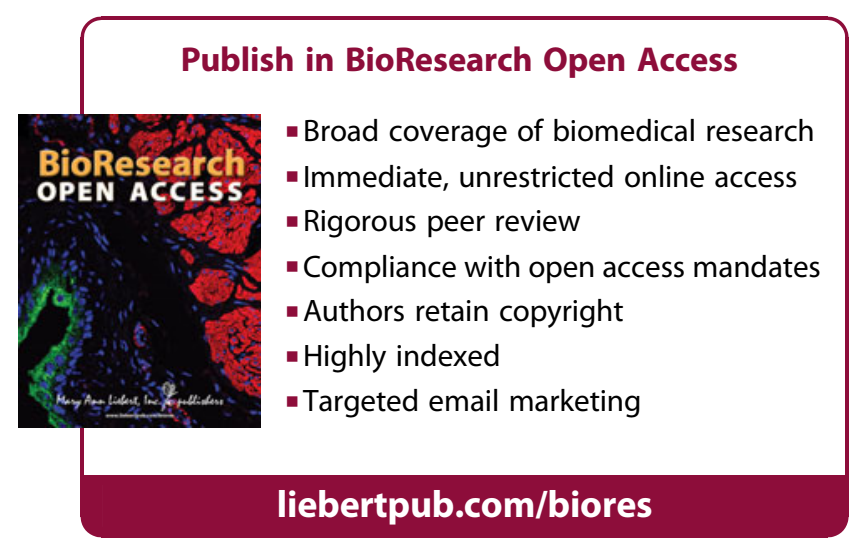

